\title{
ANTONIO LAMELA - más allá de la innovación In Memoriam
}

\section{ANTONIO LAMELA - beyond innovation In Memory}

\author{
$\underline{\text { P. Cassinello }}^{(*)}$, N. Cassinello ${ }^{(* *)}$
}

\section{RESUMEN}

La arquitectura española está de duelo. El pasado 1 de abril de 2017 falleció Antonio Lamela, uno de sus más queridos referentes. Nos ha dejado un extenso y poliédrico legado que continúa vivo en la trama urbana de nuestras ciudades, en las páginas de sus libros, y en el modelo de pensamiento y actuación, que presidido por el esfuerzo y el anhelo de innovar, le llevaron a alcanzar las cotas más altas de nuestra profesión. Un modelo con el que fundó su oficina en 1954 y que hoy, dirigida desde hace muchos años por su hijo Carlos, cuenta con una relevante representatividad internacional habiendo realizado proyectos en 32 países. Más allá de la innovación formal y tecnológica de sus edificios, -en la década de los años 50- Antonio Lamela estableció en España empresas que como Prebetong y Shokbeton contribuyeron a modernizar la construcción española, interviniendo activamente en la necesaria ampliación de «Caja de Elementos de Construcción» demandada por Le Corbusier desde los años veinte. Cambiando de escala su mirada, Antonio Lamela también nos ha legado sus pioneras reflexiones sobre la adecuada gestión de los recursos naturales y la necesaria sostenibilidad de la arquitectura de nuestro planeta dentro del cosmos en el que habita. Sera siempre un insoslayable modelo para las generaciones venideras.

Palabras clave: innovación, construcción, legado, arquitectura, sostenibilidad.

\section{ABSTRACT}

Spanish architecture is in mourning. One of its most beloved referents, Antonio Lamela passed away on April 1, 2017. He has left us an extensive and polyhedral legacy that continues to live in the urban fabric of our cities, in the pages of his books, and in the model of thought and action, which presided over by the effort and the desire to innovate, led him to reach the highest levels of our profession. A model with which he founded his office in 1954 and which today, directed for many years by his son Carlos Lamela, has a relevant international representation having carried out projects in 32 countries. Beyond the formal and technological innovation of his buildings, in the 1950s Antonio Lamela established in Spain companies such as Prebetong and Shokbeton to modernize Spanish construction, actively intervening in the necessary expansion of "Caja de Elementos of Construction" demanded by Le Corbusier since the twenties. Changing his perspective, Antonio Lamela has also bequeathed us his pioneering reflections on the proper management of natural resources and the necessary sustainability of the architecture of our planet within the cosmos in which it lives. He will always be an unavoidable model for future generations.

Keywords: innovation, construction, legacy, architecture, sustainability.

(*) Universidad Politécnica de Madrid (España)

(**) Universidad Pontificia Comillas (España).

Persona de contacto/Corresponding author: p.cassinello.p@gmail.com (P. Cassinello)

ORCID: http://orcid.org/oooo-0oo3-4592-6686 (P. Cassinello), http://orcid.org/oooo-0oo2-0322-6537 (N. Cassinello)

Cómo citar este artículo/Citation: Cassinello, P., Cassinello, N. (2017). ANTONIO LAMELA - más allá de la innovación In Memoriam. Informes de la Construcción, 69(548): e234, doi: http://dx.doi.org/10.3989/id.59961.

Copyright: (C) 2017 CSIC. Licencia / License: Salvo indicación contraria, todos los contenidos de la edición electrónica de Informes de la Construcción se distribuyen bajo una licencia de uso y distribución Creative Commons Attribution License (CC BY) Spain 3.o. 


\section{INTRODUCCIÓN}

Antonio Lamela Martínez (1926-2017) nació en Madrid el 18 de diciembre de 1926 (Fig. 1). En 1948 ingresó en la Escuela Técnica Superior de Arquitectura de Madrid /ETSAM (Fig. 2) tras haber realizado, con destacado éxito, dos años de Ciencias Exactas y un Curso Complementario que por aquellos años se exigían para poder acceder a los estudios de arquitectura. Se graduó en la ETSAM en el año 1954.

Desde la época de estudiante de arquitectura, Antonio Lamela realizó diversos viajes al extranjero que le sirvieron para ampliar sus conocimientos sobre el progreso de la arquitectura, no solo desde el punto de vista formal sino también tecnológico y empresarial. Estas experiencias unidas a la formación recibida de su padre, empresario dedicado en un principio a la fabricación del pan y posteriormente a la construcción, le sirvieron para forjar su propio modelo para el ejercicio de la profesión de arquitecto. Un modelo basado fundamentalmente en la utilidad social y la innovación formal y tecnológica, que en los primeros años estuvo teñido del color de la última Modernidad, y siempre de una admirable racionalidad y coherencia integradora, entendiendo el Estudio de Arquitectura como una empresa al servicio de la sociedad.

Tras más de seis décadas de exitosa actividad creadora y empresarial, Antonio Lamela falleció en Madrid el pasado 1 de abril de este año 2017. El Estadio Bernabéu rindió homenaje

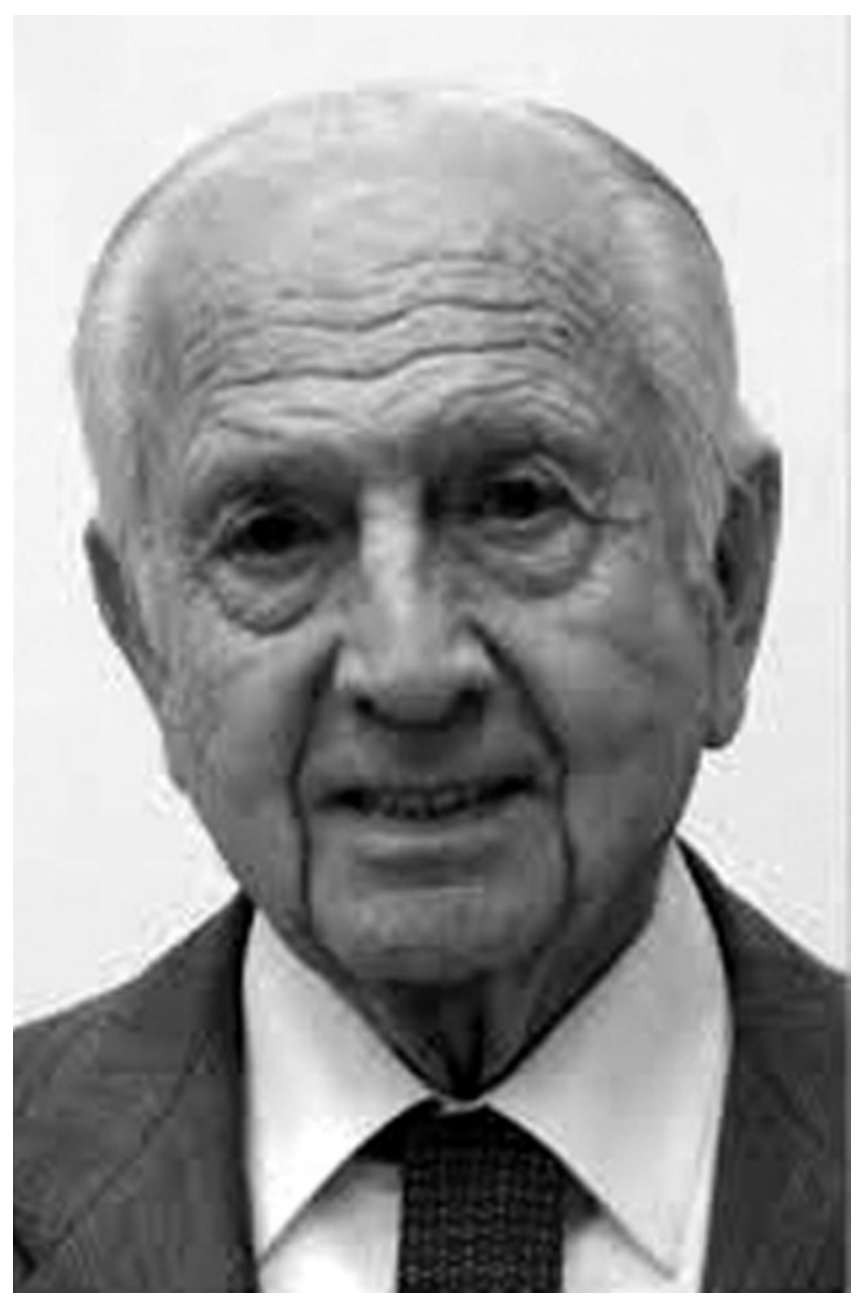

Figura 1. Antonio Lamela. a su arquitecto el día 8 de abril con un minuto de silencio antes del inicio del partido entre el Real Madrid y el Atlético, que fue retrasmitido por televisión a toda España. La Real Academia de Doctores de España le rindió un emotivo homenaje en el acto celebrado el pasado 21 de junio. Entre otros ponentes intervinieron los arquitectos Rafael de La Hoz y Luís Fernández Galiano. En nombre de toda la profesión, el Colegio de Arquitectos de Madrid /COAM organizó otro homenaje, el día 6 de julio, con la presencia de la ETSAM y el Consejo Superior de Arquitectos de España. Organismos a los que Antonio Lamela, no solo perteneció sino con los que siempre colaboró de forma desinteresada. En la mesa presidencial de este acto intervinieron; Eloy Algorri, Secretario del CSCAE, José María Ezquiaga, Decano del COAM, Manuel Blanco, Director de la ETSAM, y Carlos Lamela, Director del Estudio LAMELA. Aunque no pudieron estar presentes en este acto, Richard Rogers y Norman Foster mandaron su particular homenaje a Antonio Lamela en unas filmaciones que fueron proyectadas para toda la audiencia. Todos los asistentes fueron obsequiados por Carlos Lamela con un libro editado en homenaje a su padre (7)

La revista Informes de la Construcción, que desde la década de los años cincuenta ha publicado secuencialmente algunas de las innovadoras obras y reflexiones de Antonio Lamela (1), recoge este artículo como homenaje impreso a uno de sus más queridos colaboradores. Sus aportaciones a la arquitectura forman ya parte de la historia de esta revista nacida en 1948 -en manos de Eduardo Torroja-, con el fin de difundir y promover la innovación como motor del progreso de la sociedad. La única revista española del sector cuya demanda internacional obligó a publicar sus resúmenes en cuatro idiomas (alemán, inglés, francés e italiano) durante las décadas doradas de la última Modernidad (2).

\section{ANTONIO LAMELA- INNOVACIÓN FORMAL Y TECNOLÓGICA / 1954-2017}

Una experiencia de Antonio Lamela previa a la finalización de sus estudios fue su intervención como arquitecto, promotor y constructor -junto a su padre- en la construcción de un edificio de viviendas en la calle Segovia de Madrid (Fig. 3). Una exitosa realización que no en vano fue publicada en el número 103 de la revista Informes de la Construcción (1958) junto a destacadas innovaciones internacionales de aquel momento, como el Edificio de viviendas Lake Meadows de Chicago del célebre estudio de arquitectura americano SOM-Skidmore, Owings and Merrill. A modo de crónica anunciada, el joven Antonio Lamela iniciaba su imparable éxito profesional antes de haber terminado sus estudios.

Tal y como él comentaba siempre, fue de la mano de su padre como aprendió -de manera coherente, práctica y cabal- el proceso integral de la construcción de la arquitectura, que unido a su anhelo por innovar y a su continuo aprendizaje de la evolución de la arquitectura a nivel internacional, le proporcionó una completa formación arquitectónica y empresarial.

En el año 1954 Antonio Lamela inició su andadura profesional y fundó su propia oficina de proyectos -el Estudio Lamela-. Uno de sus primeros encargos profesionales fue el edificio de viviendas y despachos profesionales situado en la calle O’Donnell 33 de Madrid (1956-1958), que también realizó con su padre actuando como promotor. En este edificio 


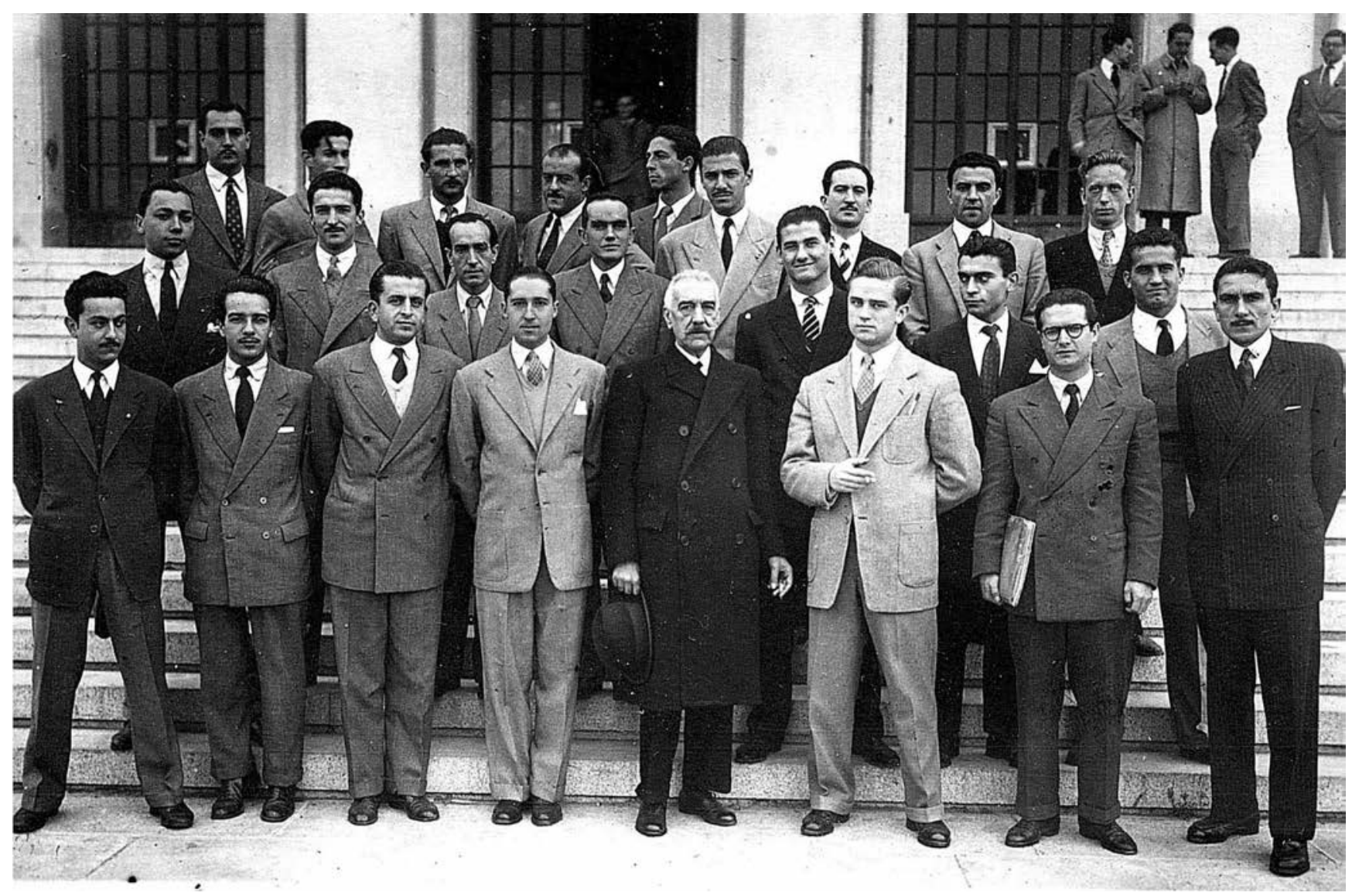

Figura 2. Curso 1948. ETSAM. Antonio Lamela fila superior, primero izquierda.

ubicó su primer Estudio profesional y su vivienda. El diseño vanguardista de este edificio le sirvió para generar admiración -profesional y social- en unos momentos en los que la arquitectura española luchaba por introducir anhelados parámetros de Modernidad. Hoy, el edificio está protegido y recogido en el DOCOMOMO como parte de la historia de nuestra vanguardia.

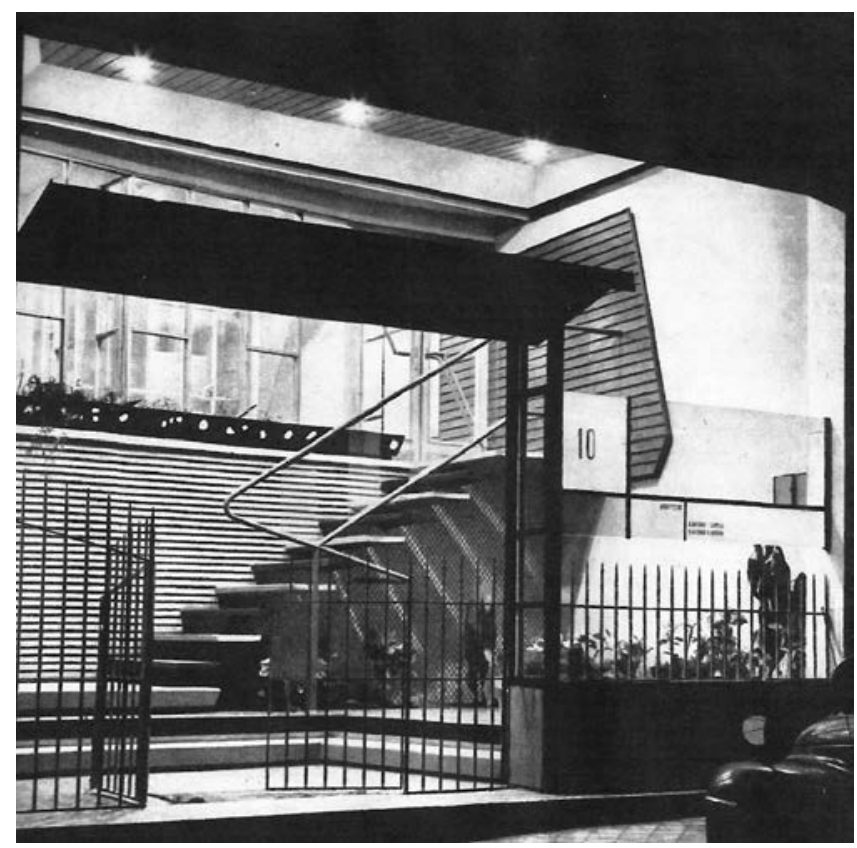

Figura 3. Portal. Edificio C/ Segovia 10. Madrid.
La escasez de longitud de la fachada del solar no impidió a Lamela proyectar un edificio inundado por la luz natural. Con este fin quebró la fachada a modo de patio abierto a la calle incorporando amplias terrazas y ventanales (Fig. 4). Dotó al edificio de modernos elementos constructivos como tabiques móviles Moderfold, ventanas Gravent, shunts, así como de instalación de aire acondicionado centralizado que en aque-

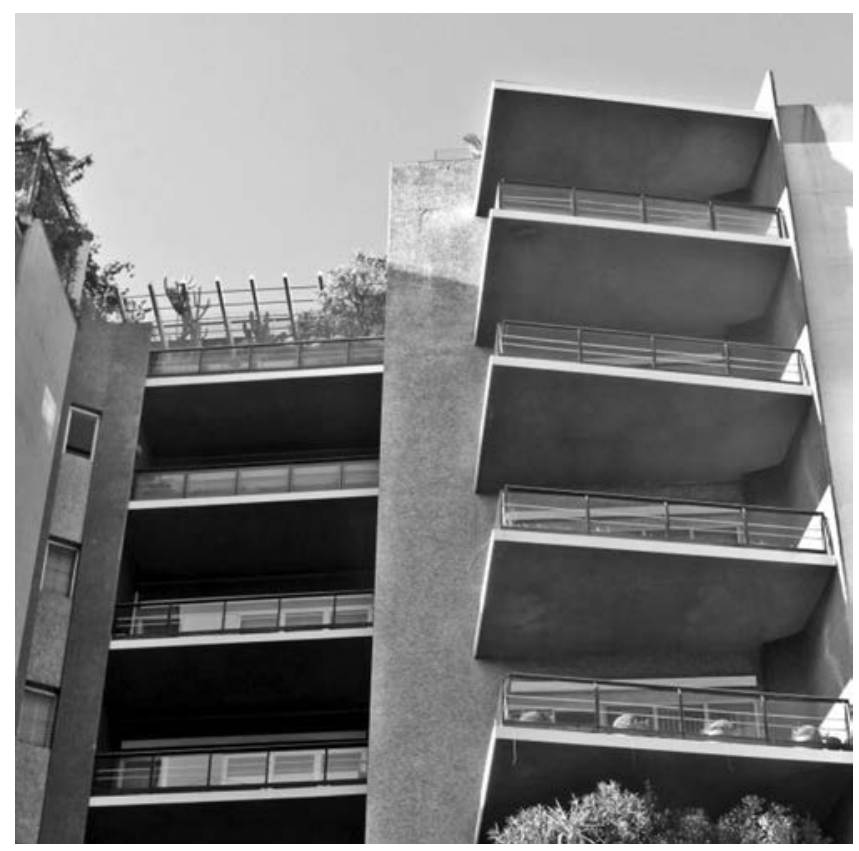

Figura 4. Edificio C/ O’Donell 33. Madrid. 
llos momentos era una lujosa e inesperada novedad en las viviendas. Utilizó el recién aparecido gresite como revestimiento de la fachada necesitando traer de Italia operarios especializados.

La industria y la técnica avanzan inconteniblemente ofreciéndonos sus codiciados frutos, permitiéndonos nuevas formas y también la solución de problemas que antes no podíamos afrontar. Antonio Lamela 1958.

No conforme con la ausencia en España de gran parte de los avances técnicos de los que ya disfrutaban en otros países, Antonio Lamela estableció un estrecho contacto profesional con el Instituto Técnico de la Construcción y del Cemento dirigido por Eduardo Torroja, que desde su fundación en 1934 protagonizó la creación de la necesaria «Caja de Elementos de Construcción» demandada por Le Corbusier desde la década de los años veinte.

Baste recordar aquí brevemente como Le Corbusier en su polémico libro «Hacía una Nueva Arquitectura» denunció el hecho de que la Arquitectura no respondía a las necesidades que demandaba la nueva sociedad, no solo en cuanto se refiere a los espacios habitables proyectados, sino también a los artesanales sistemas constructivos utilizados. Por ello declaró la necesidad de crear la entonces inexistente «Caja de Elementos de Construcción» que haría posible la industrialización de la Nueva Arquitectura (3). En el primer congreso CIAM de 1928 quedo claro que la «Nueva Arquitectura» no era un nuevo estilo arquitectónico, se trataba del nacimiento de un nuevo modelo de pensamiento, de proceder, de proyectar, de fabricar, de construir. Habría un antes y un después, de que la Arquitectura estuviera ligada directamente a los avances de la Ciencia y de la Técnica. No en vano, Lucio Costa lo definió como el cambio más importante de la Historia de la Arquitectura, comentando que a partir de entonces, la aventura humanística del Renacimiento podría aparecer en la Historia como un simple juego de intelectuales complicados (4).

En España fue sin duda el Instituto de Eduardo Torroja -crisol científico de la Modernidad- quien protagonizo la creación de esa «Caja de Elementos de Construcción» apoyando a los profesionales e industrias en la racionalización de sus procesos de producción, el desarrollo de nuevas patentes así como en la relevante tarea de establecer en España patentes extranjeras, que seleccionaba en el mercado internacional y difundía desde su revista Informes de la Construcción. Algunos arquitectos, ingenieros, empresarios e industriales españoles, entre otros; Antonio Lamela, Fernando Cassinello, Rafael de La-Hoz, Miguel Fisac, Ricardo Barredo, Vicente Peiró, Idelfonso Sánchez del Río, o el propio Eduardo Torroja se implicaron directamente en esta ilusionante y necesaria tarea.

En 1965 Antonio Lamela introdujo en España los hormigones preamasados a través de la firma Prebetong en unos momentos en los que en España todavía era una práctica habitual preparar el hormigón a pie de obra mediante pequeñas hormigoneras. Pocos años después, en 1968 estableció en España la pionera compañía Schokbeton, creada en 1935 en Holanda y dedicada a la prefabricación de elementos arquitectónicos de hormigón armado. Una patente que fue difundida en 1957 (5) por el Instituto Torroja a través de su revista Informes de la Construcción (Fig. 5). Su establecimiento en España abrió nuevas posibilidades de diseño y modelos de negocio adaptados a la precaria situación económica de aquellos años (6).

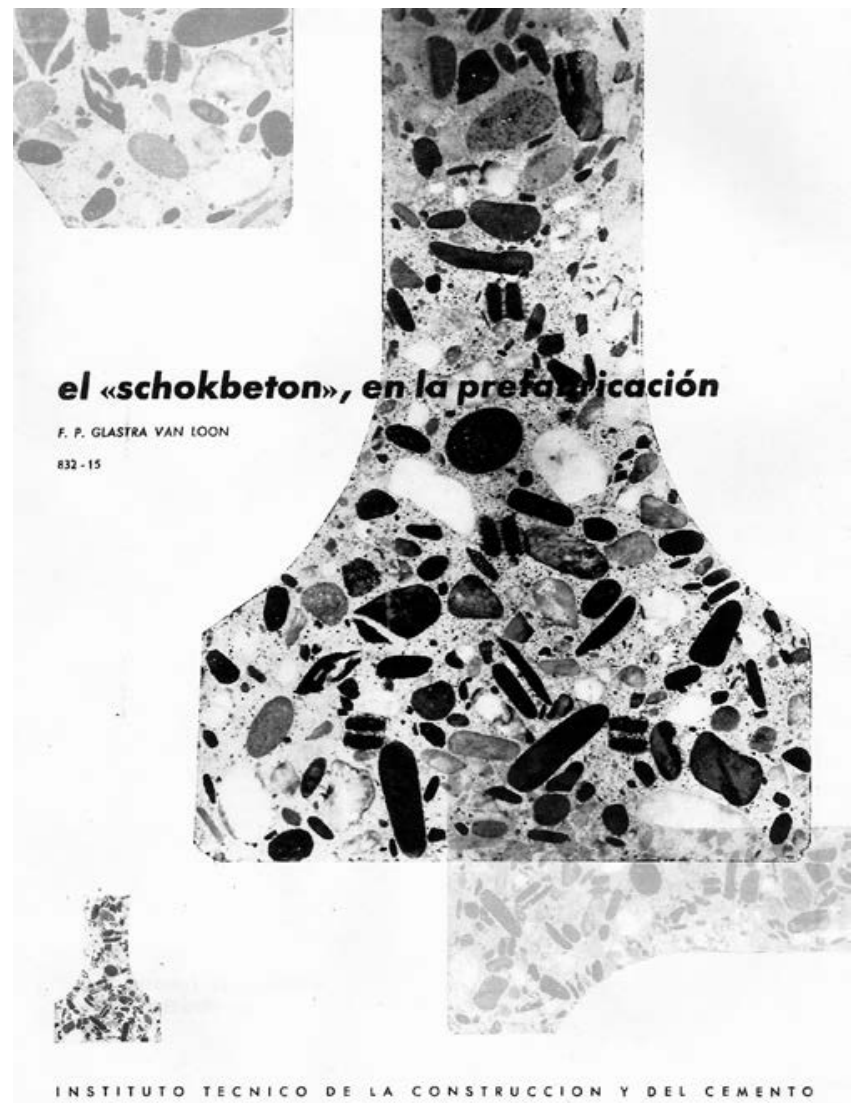

Figura 5. Schokbeton. IETcc 1957.

Un destacado ejemplo de las realizaciones de esta empresa fueron los elementos prefabricados de hormigón armado de la facha del Edificio Beatriz (1968-1976) proyectado por el arquitecto Eleuterio Población.

Antonio Lamela contribuyó también a modernizar y racionalizar algunas industrias españolas del sector. Con este fin creó la empresa CTC dedicada al empaquetado de ladrillos, que se servían directamente desde la fábrica en palés y no como hasta entonces, que eran recibidos en obra «a granel» en camiones volquete. Desde su visión integradora Antonio Lamela creó también la primera sociedad de Project Management en España a la que denominó «Gestión y Control 73". También fundó la empresa ADI internacional, integrado en ella las actividades profesionales de arquitectura, decoración e ingeniería, y para ello se asoció con el interiorista Luís Moreno de Cala y los ingenieros Alberto Viti, Carlos Fernández Casado, Javier Manterola y Leonardo Fernández Troyano (7).

De manera solapada con estas actividades empresariales, y con el mismo espíritu innovador e integrador que subyace en ellas, Antonio Lamela proyectó y construyó innumerables edificios innovadores de muy diferentes usos, caminando siempre de la mano de los avances que la técnica iba alcanzando. Fue pionero en la arquitectura turística española, diseñando innovadores hoteles, edificios de apartamentos y zonas residenciales en la Costa del Sol y en Mallorca. En pocos años convirtió el Estudio Lamela en uno de los más importantes de España.

$\mathrm{Al}$ inicio de la década de los años sesenta, debido el gran crecimiento de sus encargos profesionales necesitó ampliar el espacio de sus oficinas. Con este fin adquirió, con otros so- 


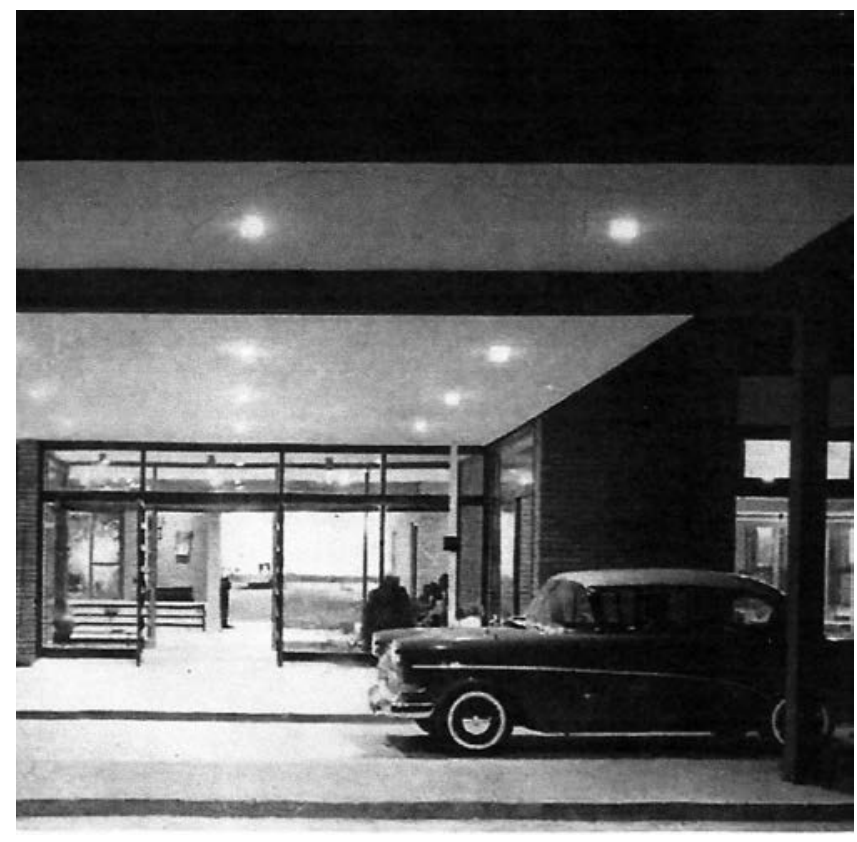

Figura 6. Motel El Hidalgo 1959.

cios, la propiedad de la calle O'Donnell 34, realizando un vanguardista proyecto de edificio exclusivo de oficinas. El 1 de abril de 1966 inauguró en él las nuevas oficinas del Estudio Lamela.

Entre otros muchos edificios realizó; Edificio de Viviendas en calle O’Donnell 33 (Madrid 1956), Oficinas Swissair (1956), Motel El Hidalgo (1959) (Fig. 6), Conjunto Roca Marina, Edificio La Caleta (Fig. 7) y Apartotel Magalluf (Palma de Ma-

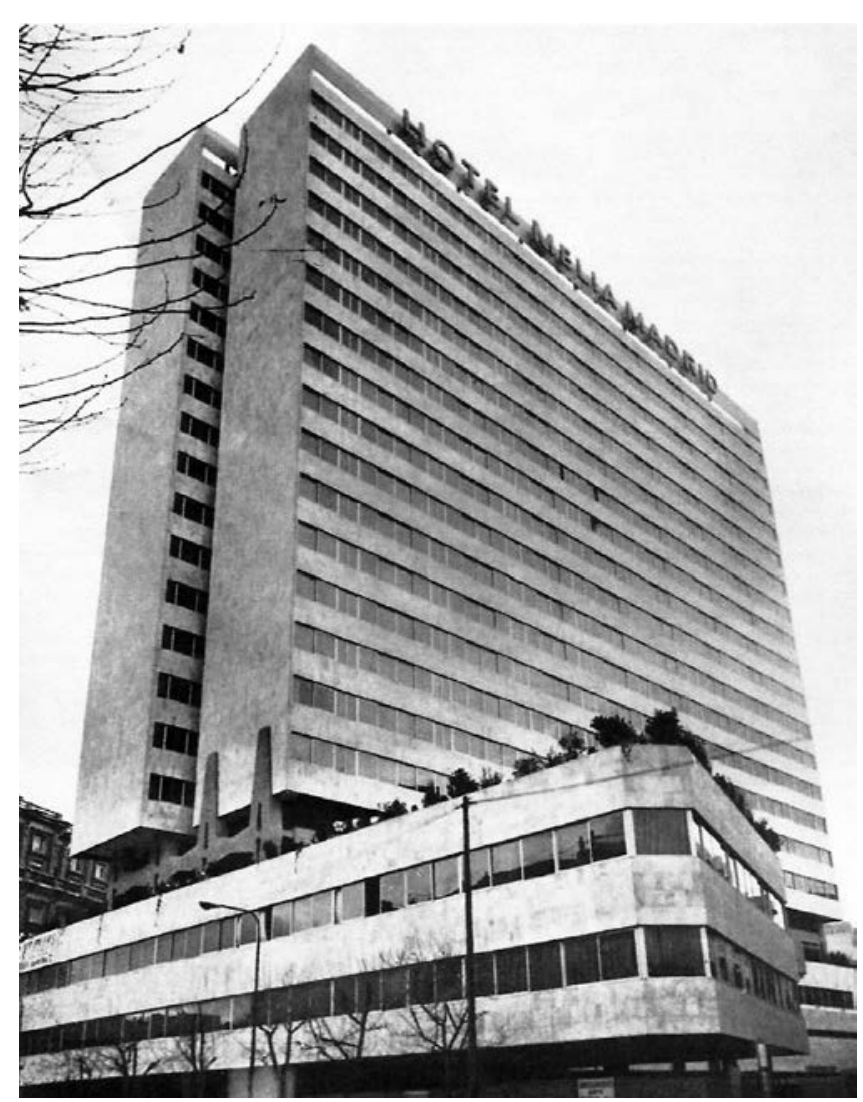

Figura 8. Hotel Melia Princesa 1963.

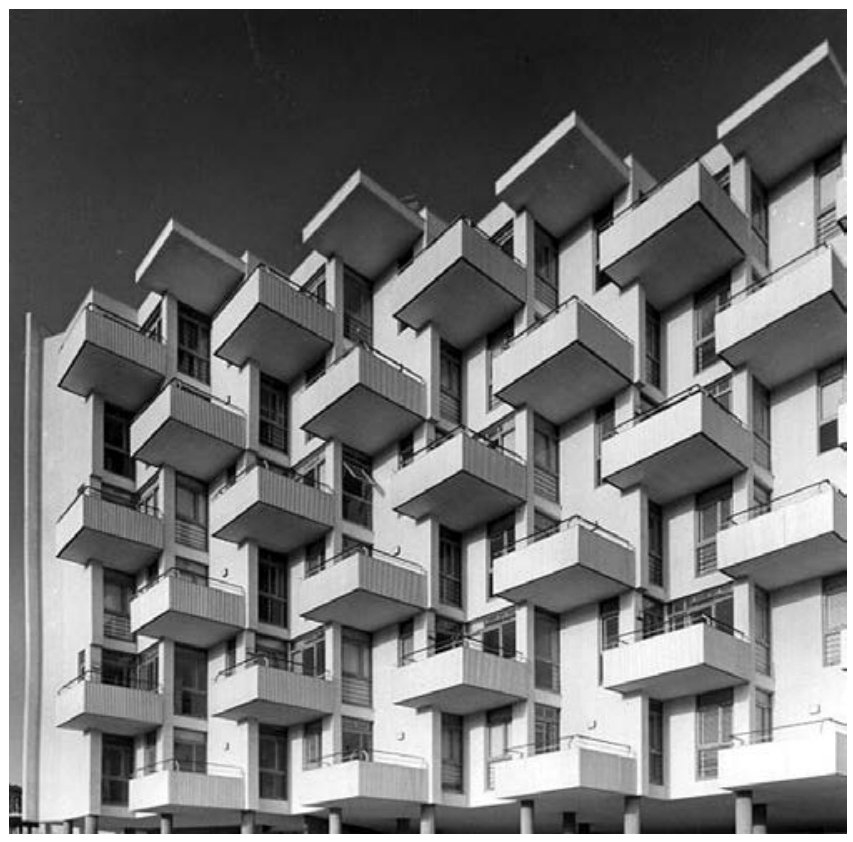

Figura 7. Edificio La Caleta 1962.

llorca 1962), Hotel Meliá Princesa (Madrid 1963) (Fig. 8), Conjunto Playamar, La Nogalera y Hotel Meliá en Torremolinos (Málaga 1963), Oficinas en calle O’Donnell 34 (Madrid 1964), Barrio San Ignacio de Loyola (Madrid 1964-1970), Torres Colón (Madrid 1967-1976), Conjunto Galaxia (Madrid 1965) (Fig. 9), Edificio Pirámide (Madrid 1972) (Fig. 10), Edificio bancario en calle Génova 27 (Madrid 1973), Condominio Laroc, Florida (Estados Unidos 1984), Ampliación y remodelación del estadio Santiago Bernabéu (1988-1993) y (2002-2005), Nueva Terminal T4 del Aeropuerto de Barajas en colaboración con Richard Rogers (Madrid 1997-2006).

En la década de los años ochenta el Estudio Lamela había crecido considerablemente y contaba con una muy extensa plantilla en la que se integraban profesionales de muy diferentes países y disciplinas, entre otros; arquitectos, ingenieros civiles, ingenieros industriales, e interioristas. Fue en el año

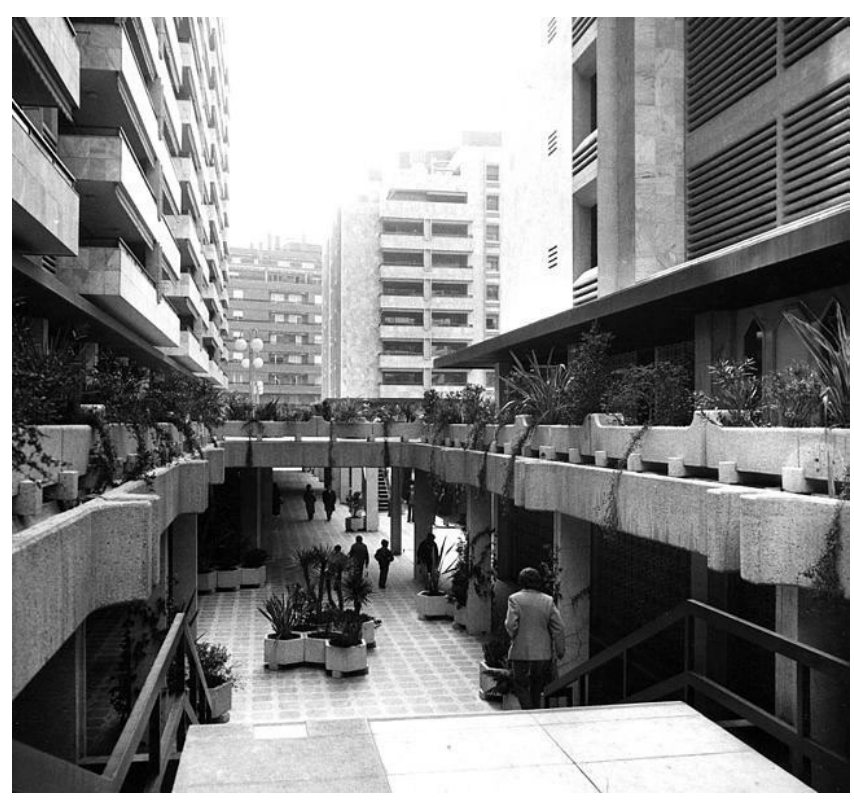

Figura 9. Conjunto Galaxia 1965. 


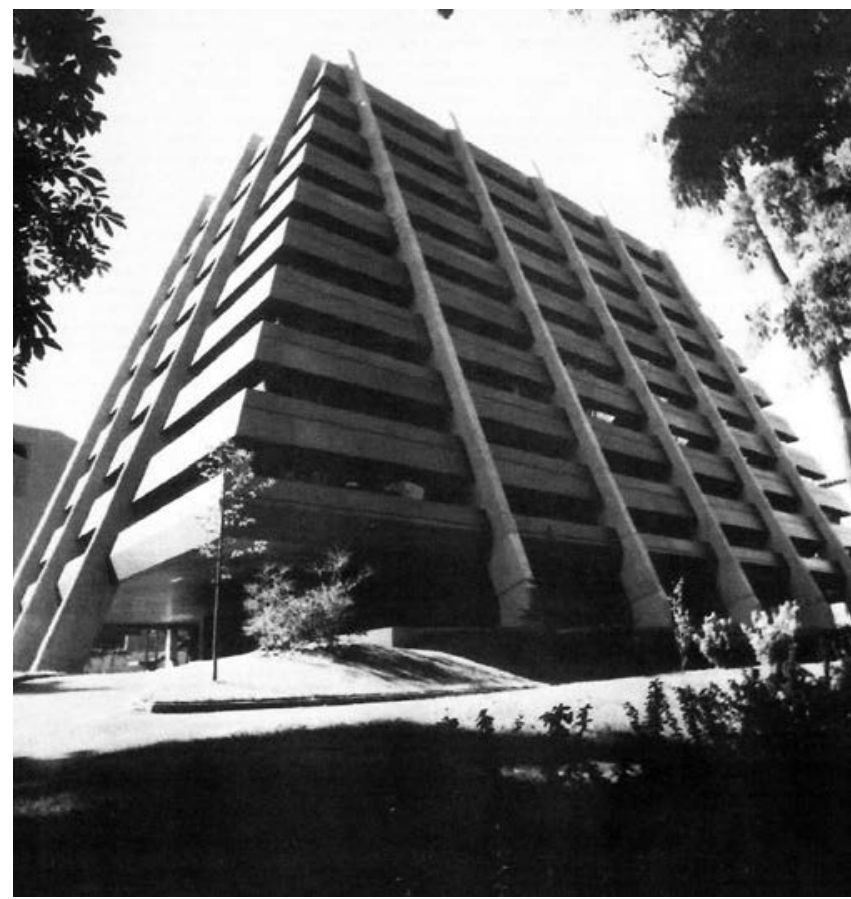

Figura 10. Edificio Pirámide 1972

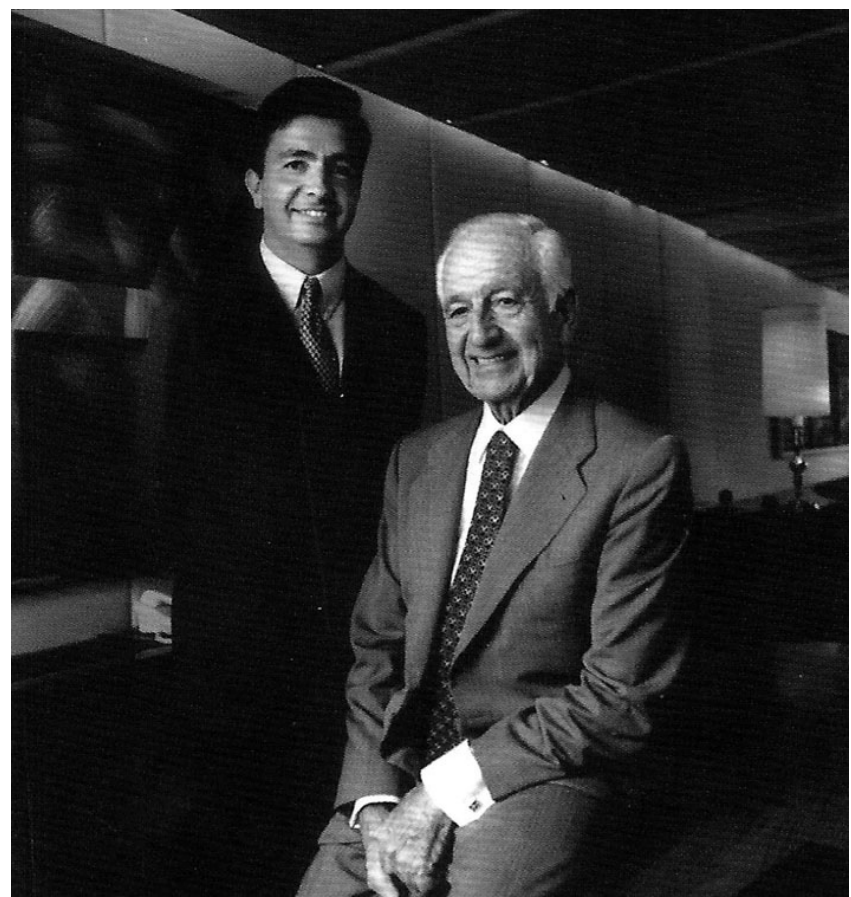

Figura 11. Antonio Lamela y su hijo Carlos.
1984 cuando su hijo Carlos se incorporó al Estudio Lamela tras haber terminado su carrear de arquitectura en la ETSAM en 1981 y tras haber realizado el postgrado de la UIA en Florencia Fig. 11. Desde entonces, no solo participó en todos los proyectos, sino que pronto fue el director del desarrollo de los mismos, tanto en España como en el extranjero.

Una actuación de gran relevancia y repercusión social fueron las dos ampliaciones del Estadio Santiago Bernabéu (Fig. 12), pero sus más icónicos edificios son sin duda; de la primera época Torres Colón proyectadas en 1967, y de sus últimas obras la Terminal T4 del Aeropuerto de Madrid-Barajas.

Torres Colón fue un pionero edificio colgado de 23 plantas ejecutado con un admirable lenguaje de Modernidad. Desde el inicio de su construcción generó un gran asombro y curiosidad, no solo en el mundo técnico sino también a nivel popular. No en vano se trataba del primer edificio colgado que se construía en España y uno de los primeros en el resto del mundo (Fig. 13). En el año 1968 se inició su construcción y también la de otras innovadoras estructuras colgadas como la del Standard Bank Central de Johannesburgo diseñada por el arquitecto E.W.N. Mallow y los ingenieros Ove Arup (30 plantas) (Fig. 14), y la del Westcoast Transmission Company Tower en Vancouver de los arquitectos Rhone - Irealde (13 plantas) (Fig. 15).

La escasa experiencia en el diseño y construcción de edificios colgados convirtió a Torres Colón en una ilusionante aventura para todos los que participaron. Funcionalmente el hecho de colgar el edificio permitía optimizar el espacio, no solo sobre rasante sino también bajo rasante, dotando de una estructura independiente a las plantas de sótano destinadas a aparcamiento. Con este innovador sistema estructural tan solo hay que cimentar los núcleos centrales de los edificios de los que cuelgan las plantas sobre rasante mediante tirantes o péndolas ubicadas en el perímetro de las plantas y, en el caso de Torres Colón, ancladas a una plataforma de coronación del núcleo que esta volada sobre este (Fig. 13). En la definición y construcción de esta pionera estructura intervinieron los ingenieros Carlos Fernández Casado, Javier Manterola y Leonardo Fernández Troyano. La empresa constructora fue HUARTE y Cia. El director de la supervisión de las obras fue Amador Lamela, hermano de Antonio Lamela, que se incorporó al Estudio en 1970 tras terminar la carrera de arquitectura en la ETSAM.

Tal y como Javier Manterola explicó, una de las mayores dificultades de realizar un edificio colgado es que tenga mucha esbeltez de forma -gran altura y reducida planta-, ya que el problema resistente de estos edificios lo constituye la desnivelación de los apoyos entre las zonas que apoyan en el núcleo y las que están suspendidas de los tirantes, y cuantas más plantas tenga el edificio mayor es esta desnivelación (8). En el caso del Standar Bank de Johannesburgo este problema se minoriza al colgar las 30 plantas en tres grupos de 10 plantas (Fig. 14). En el caso de la Westcoast Transmission Company Tower de Vancouver su esbeltez de forma es menor y menor su número de plantas, que se cuelgan directamente del núcleo de hormigón mediante la introducción de tirantes inclinados (Fig. 15).

El proceso de construcción de Torres Colón se inició con la construcción de los núcleos de hormigón armado de ambos edificios y posteriormente de sus plataformas de coronación. Bajo estas se colocó la cimbra para la ejecución de los forjados de piso, iniciándose la construcción por el forjado más alto (9). Secuencialmente se iba bajando la cimbra y construyendo los forjados inferiores (Fig. 16). Los tirantes que soportan las diferentes plantas de los edificios fueron diseñados enfatizando la esbeltez de los edificios. Se trata de elementos prefabricados en hormigón armado de sección $42 \times 42 \mathrm{~cm}$, con un orificio central en cuyo interior se introducían los cables de pretensado. De esta manera quedaban ya protegidos contra incendios. La longitud de cada pieza prefabricada es de $5,9 \mathrm{~m}$, la altura correspondiente a dos plantas. Su superfi- 


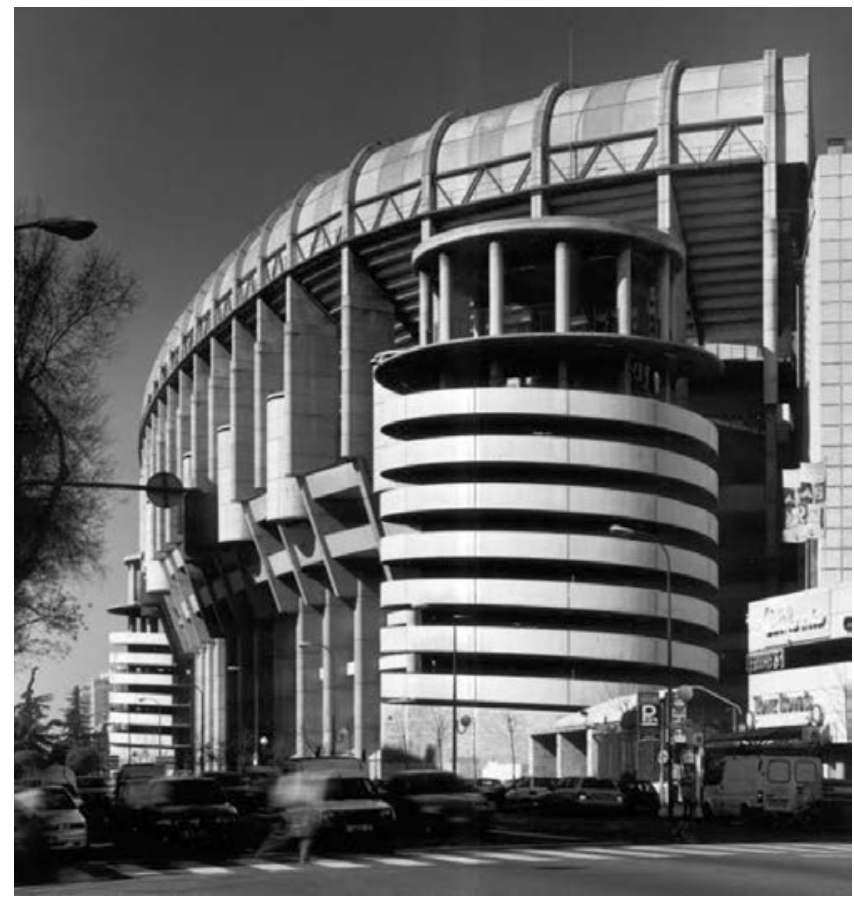

Figura 12. Ampliación del Santiago Bernabéu.

cie es estriada marcando la verticalidad de las piezas, y mostrando en su conjunto la esbeltez del edificio suspendido. Un aspecto en el que Antonio Lamela puso especial interés (8) (Fig. 17).

Desde el día de su inauguración, Torres Colón, se convirtió en uno de los más destacados hitos de la Arquitectura Moderna madrileña. En 1975 el Instituto Eduardo Torroja las presentó en el Congreso Mundial de Arquitectura y Hormigón Pretensado celebrado en Nueva York donde fue reconocido como el edificio construido con la tecnología más avanzada hasta el momento (11).

Otra de las más emblemáticas obras de Antonio Lamela es sin duda la Terminal T4 del Aeropuerto de Madrid-Barajas realizada por el Estudio Lamela en colaboración con el arquitecto Richard Rogers y las ingenierías Initec y TPS, que obtuvo el Premio Stirling de Arquitectura 2006. Esta nueva terminal fue adjudicada mediante un Concurso Público en el año 1997, su construcción se realizó entre 2000 al 2005 y fue inaugurada en el año 2006. Es uno de los proyectos más grandes construidos en Europa. Consta de dos terminales la denominada T4, el Edificio Satélite, T4S, así como un aparcamiento para 9.000 vehículos, con más de un millón de metros cuadrados en su totalidad (12).

Se trata nuevamente de una admirable arquitectura de vanguardia, que tal y como Antonio Lamela explicó, es el resultado del perfecto engranaje de colaboración entre una gran multitud de profesionales especialistas en los diversos aspectos que la arquitectura demanda (13). La estructura está formada por pilares y vigas postesadas de hormigón armado, de las que nacen los soportes metálicos de los que sostienen las sinuosas vigas principales de la cubierta (14) (Fig. 18).

La secuencia continua de los módulos de la cubierta ondulada, cuyos soportes circulares metálicos se pintaron de diferentes colores, es la imagen que imprime carácter al conjunto

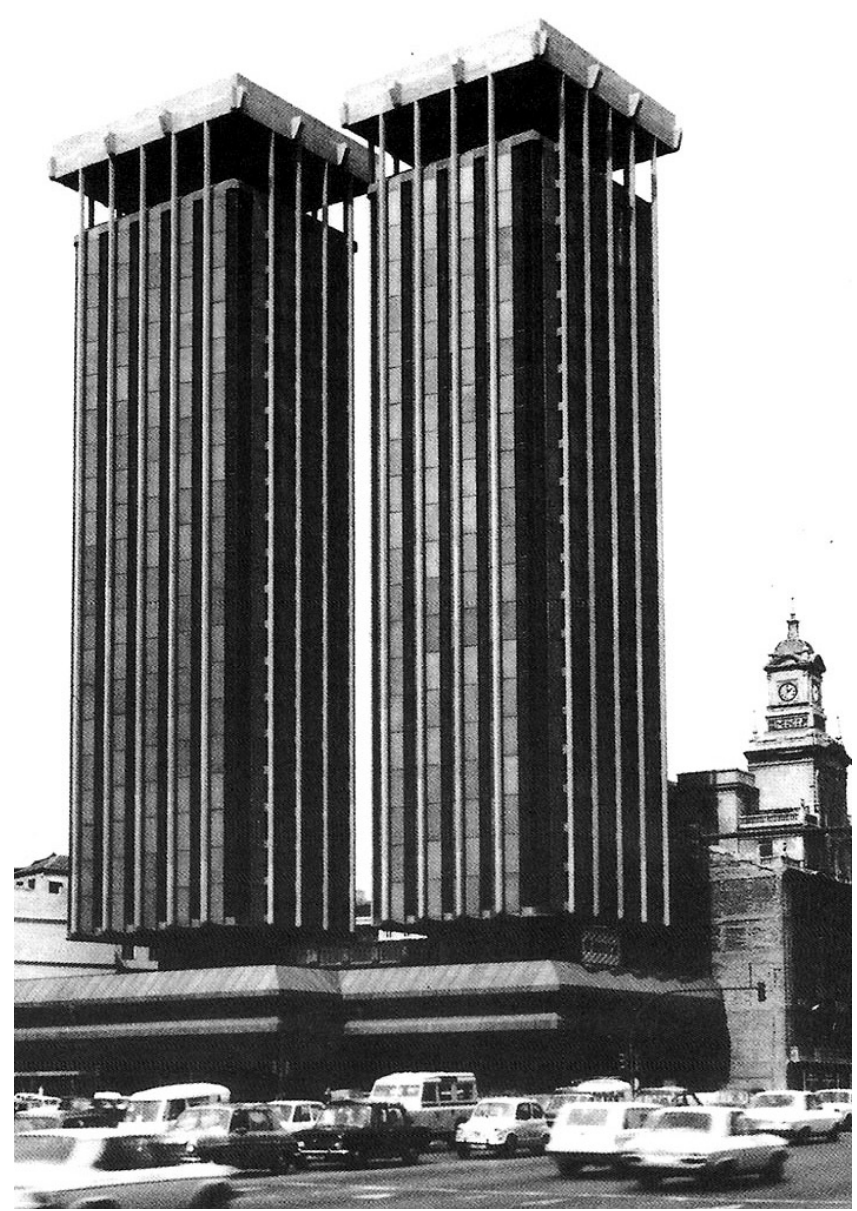

Figura 13. Torres Colón/ 23 plantas.

de esta enorme terminal. Su linealidad responde sencillamente a la demanda del buen funcionamiento de un aeropuerto, ofreciendo una gran longitud de embarque y desembarque de pasajeros, con un dique principal que alcanza $1.142 \mathrm{~m}$. Una modulación que permitiría su fácil ampliación con tan solo ir añadiendo nuevos módulos ondulados. Las fachadas son también un elemento destacable, cuya sencillez completa la atractiva imagen formal del conjunto. Se trata de una fachada ejecutada mediante un muro cortina de vidrio colgada de la cubierta, que esta tesada para poder absorber los esfuerzos de viento y estabilizar el conjunto (Fig. 19). Interiormente es también la cubierta la que marca el ritmo y definición sensorial del espacio. Su intradós está revestido de láminas de madera de bambú, y cuenta con grandes lucernarios circulares ubicados secuencialmente en el centro de los diferentes módulos. Los pilares metálicos que la sostienen tienen forma de Y de gran inclinación y se prolongan hasta las plantas inferiores entre grandes vacíos permitiendo el paso de la luz natural.

En el año 2005 se unió al conjunto de la nueva Terminal T4 el llamado Pabellón de Estado, cuya estructura de cubierta fue realizada por la oficina alemana schlaich bergerman und partner (15).

\section{GEOÍSMO Y COSMOÍSMO}

Antonio Lamela fue un pionero visionario de la necesaria globalización y sostenibilidad de las actuaciones del hombre en nuestro planeta. Tras la Segunda Guerra Mundial, mientras la arquitectura centraba su interés en la demanda social de 


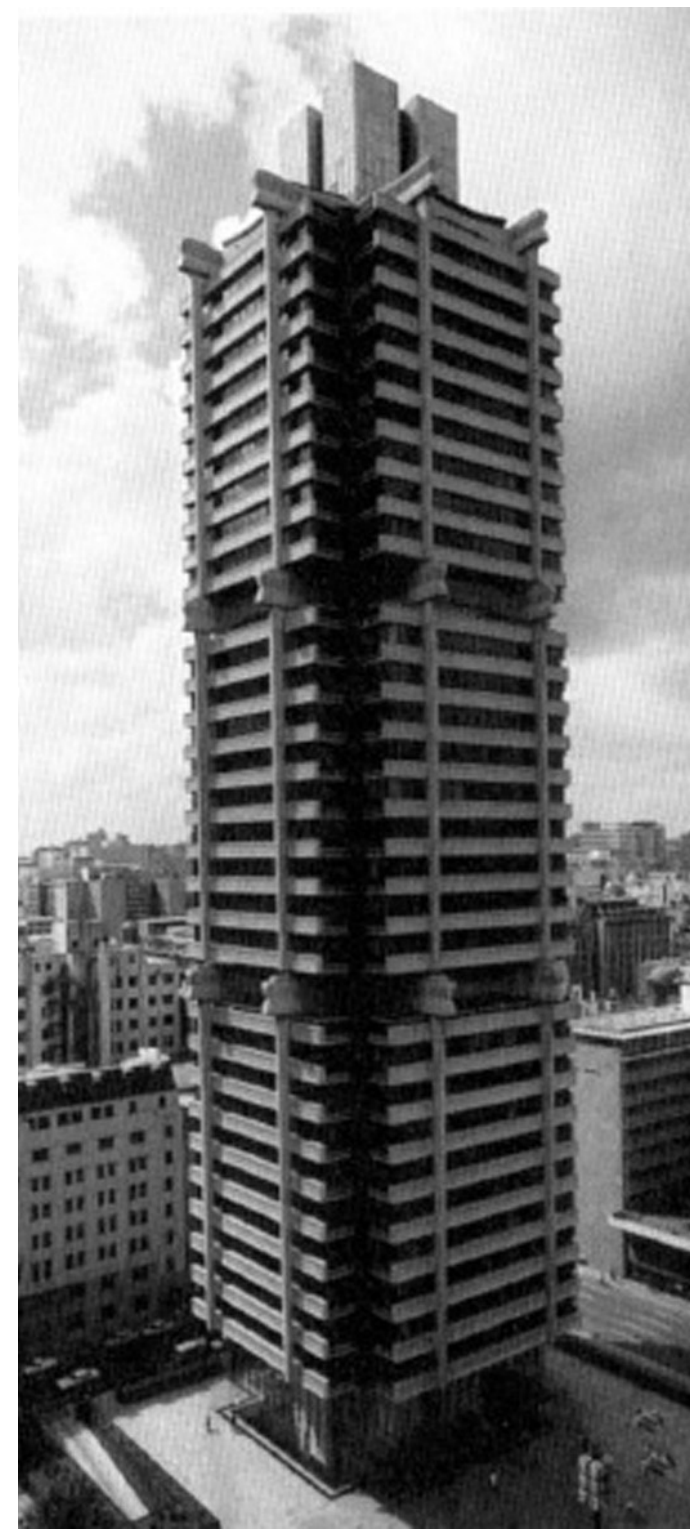

Figura 14. Standard Bank / 30 plantas.

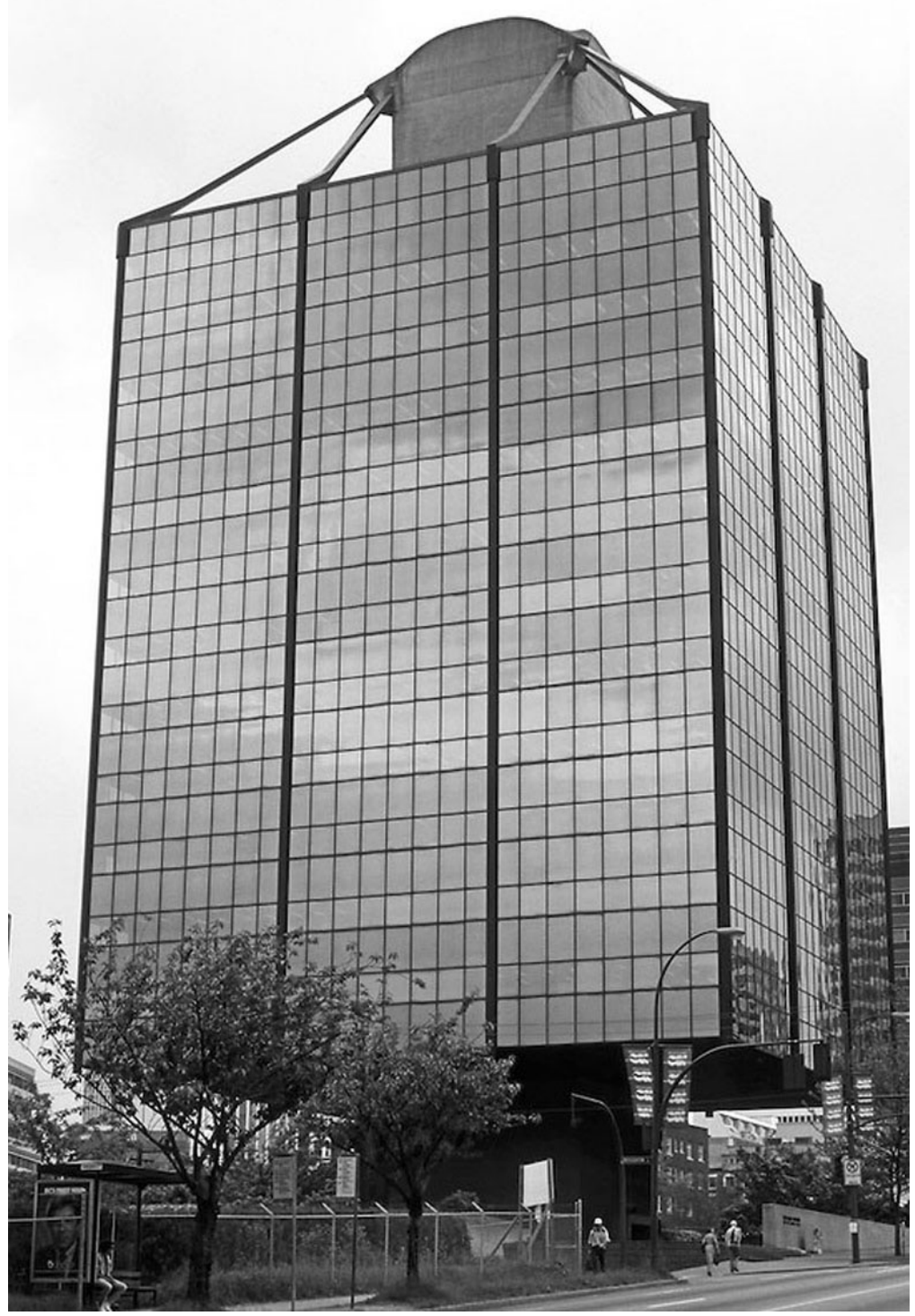

Figura 15. W.T / 13 plantas.
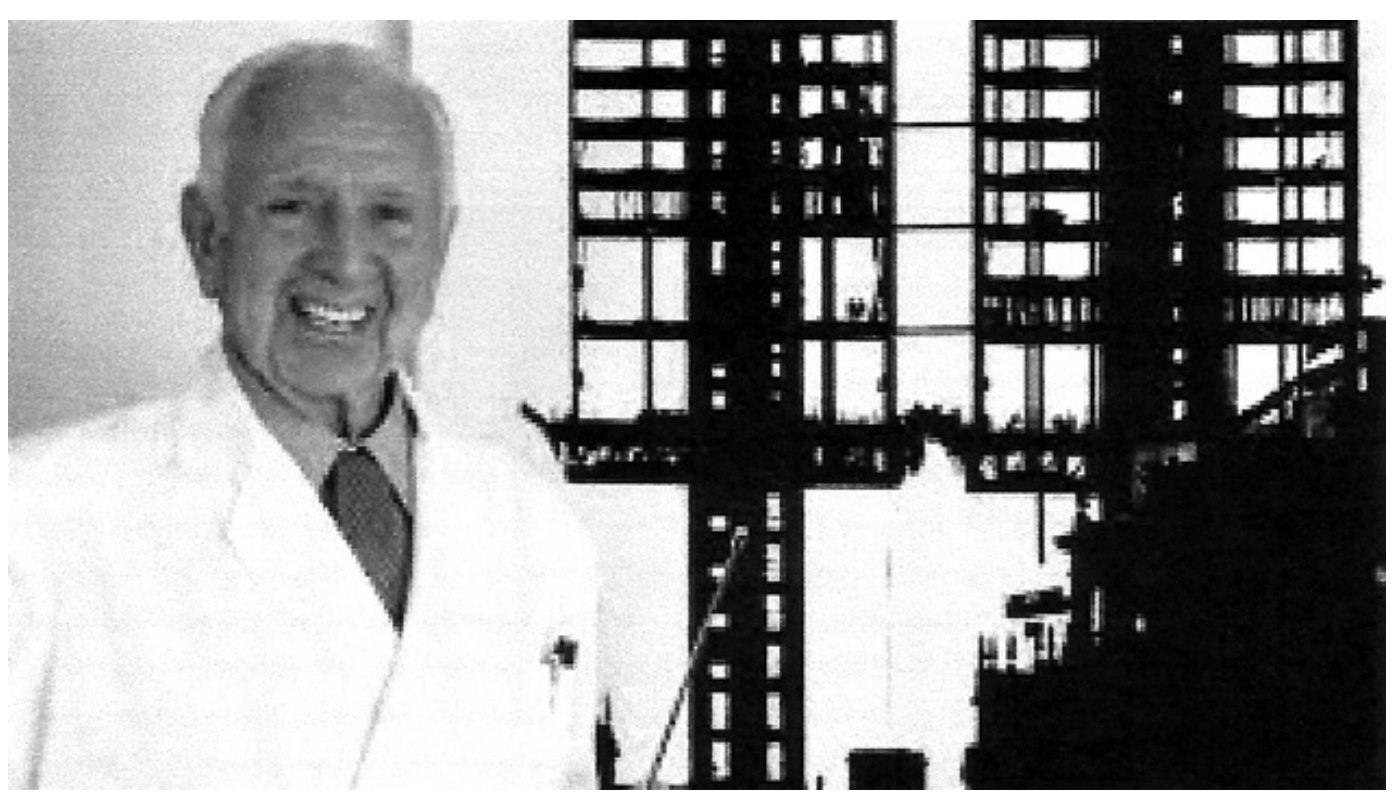

Figura 16. Antonio Lamela - Torres Colón al fondo. 


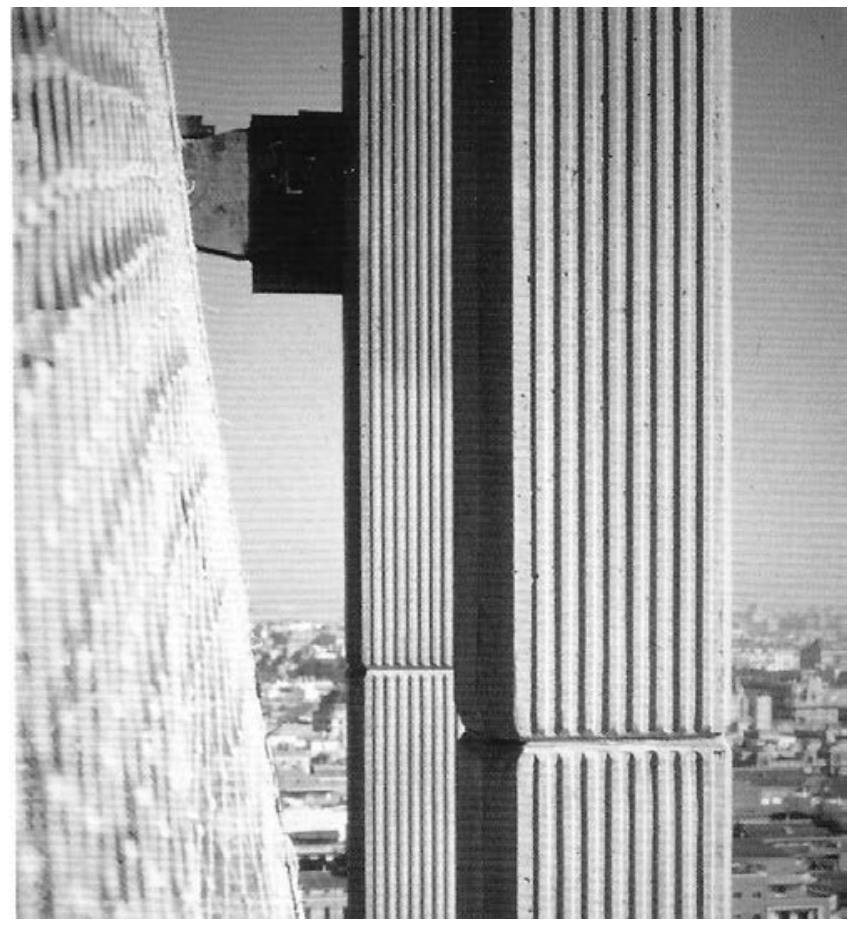

Figura 17. Péndolas.

reconstrucción del hábitat y la ciudad, en la década de los años 50, Antonio Lamela inició sus reflexiones y planteamientos de dos nuevas disciplinas a las que denominó -Geoísmo y Cosmoísmo- (16).
Denominó "Geoísmo» a una nueva rama de la Ciencia cuyo objetivo es ordenar la utilización del planeta Tierra en su conjunto y «Cosmoísmo» a la encargada de ordenar y regir la utilización del espacio exterior -el Cosmos- en el que habita nuestro planeta. Además de sus libros, artículos y conferencias sobre estos temas, Antonio Lamela centro en ellos su discurso de ingreso en la Real Academia de Doctores, que avalado por Rafael de La Hoz, leyó el 13 mayo 1998.

El progreso humano requiere un cambio de mentalidad $y$ de corazón, así como un nuevo sentido de interdependencia global y corresponsabilidad universal, con apreciación holística1. Es preciso desarrollar, con imaginación, una novedosa visión de vida sostenible, de forma simultánea a niveles local, nacional, regional y mundial. Antonio Lamela 1998.

\section{PREMIOS Y DISTINCIONES}

A lo largo de su vida Antonio Lamela recibió múltiples reconocimientos, premios y distinciones, entre otros: 1998, Miembro de Número la Real Academia de Doctores de España. 2005, Gran Cruz de la Orden del Mérito Civil. 2005, Medalla de Oro al mérito en el Trabajo. 2006, Premio Rey Jaime I «Urbanismo, Paisaje y Sostenibilidad». 2006, Miembro del Alto consejo Consultivo en Investigación, Desarrollo e Innovación. Valencia. 2006, Presidente del Consejo Académico de la universidad Camilo José Cela. 2006, Premio Stirling. T4 Aeropuerto de Madrid-Barajas. 2006, Premio de Urbanismo, Ayuntamiento de Madrid. 2007 Profesor Doctor «Honoris Causa», Universidad Camilo José

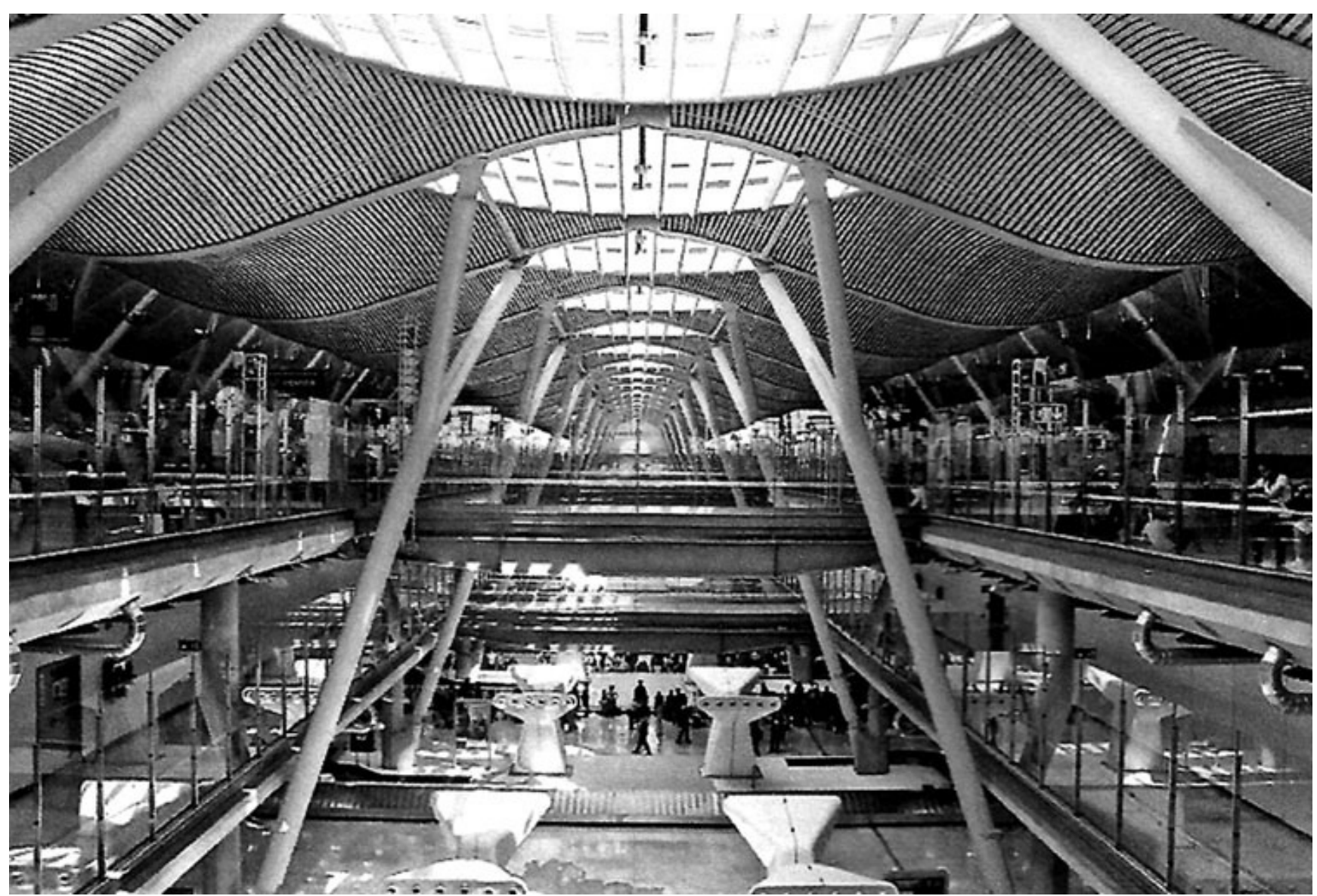

Figura 18. Interior T4. Aeropuerto de Madrid-Barajas. 


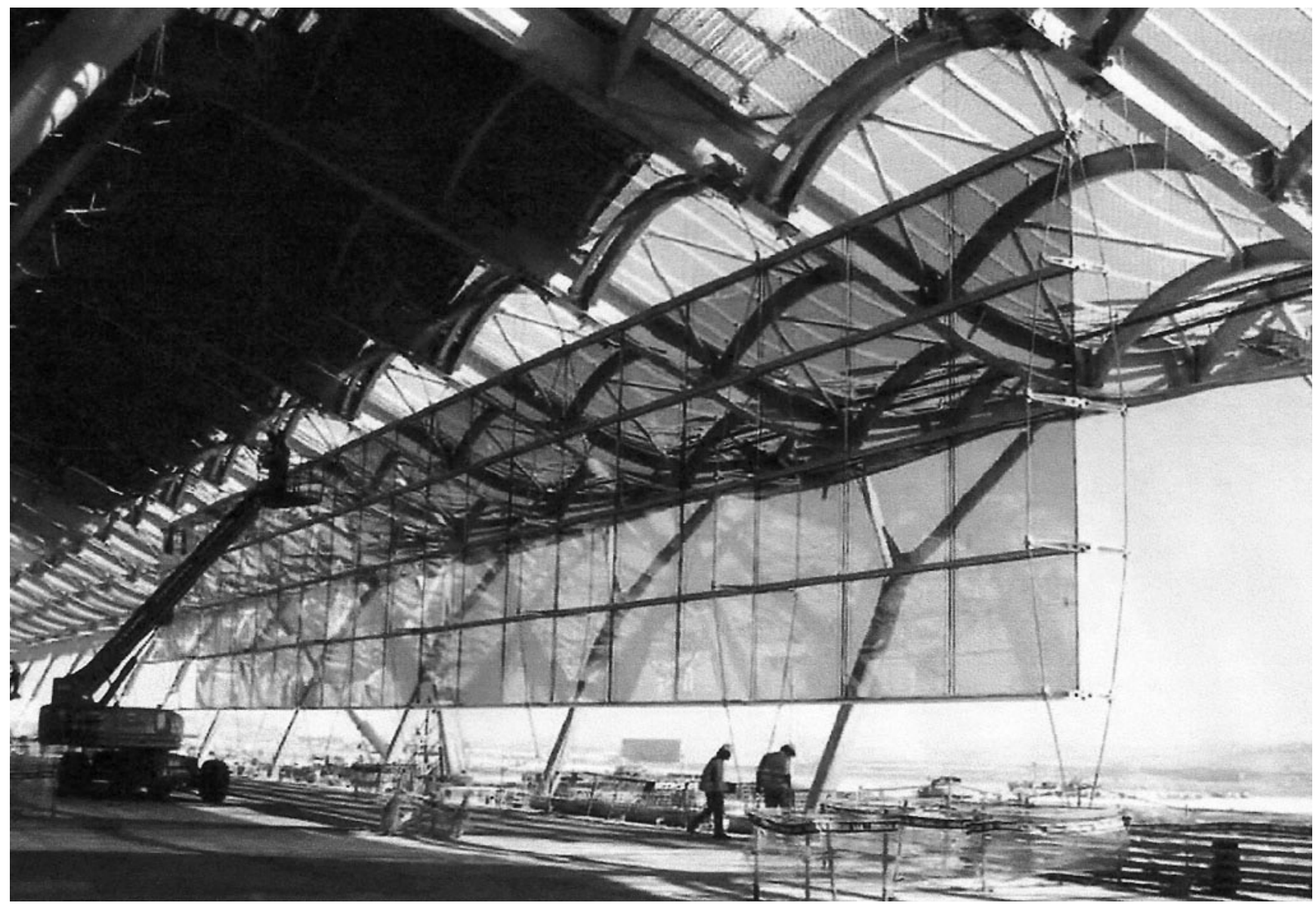

Figura 19. T4. Facha de vidrio postesada.

Cela. 2010, Premio a la Excelencia Europea, Comunidad de Madrid. 2010 Colegiado de Honor del Colegio Oficial de Arquitectos de Madrid/COAM. 2011, Miembro Fundador de ALUMNIA, Asociación de Antiguos Alumnos de la ETSAM, Escuela técnica Superior de Arquitectura de la Universidad Politécnica de Madrid.

\section{INSOSLAYABLE AFÁN}

Su incansable afán por intervenir de manera activa en el progreso de la sociedad, unido a su desmedida generosidad, le llevó a colaborar con muy diferentes organismos, instituciones, fundaciones, y universidades a las que prestó su apoyo de manera desinteresada. Entre estas actividades cabe destacar su colaboración con la Fundación Eduardo Torroja y con la Escuela Técnica Superior de la Universidad Politécnica de Madrid.

En el año 2010 colaboró con la Subdirección de Alumnos, participando en el homenaje del centenario del nacimiento de Félix Candela organizado por la ETSAM, UPM y la Fundación Juanelo Turriano. Escribió un interesante artículo (17) en el libro catálogo de la Exposición «Félix Candela-La Conquista de la Esbeltez», que fue presentado en el Círculo de Bellas Artes de Madrid, junto a su comisaria Pepa Cassinello y otros autores colaboradores como Javier Manterola y José Calavera. En el año 2011 viajó con nosotros para presentar la exposición en la Technischen Universität de Berlin, invitados por el profesor y amigo Mike Schlaich, y acompañados por José Antonio Torroja y José Calavera. Ese mismo año, en el mes de marzo la exposición se trasladó al Deutsche Museum de Munich por invitación de su Director de Exposiciones Dirk Bühler con la colaboración del Instituto Cervantes de Munich. Fue la primera exposición española expuesta en este importante Museo de Tecnología (Fig. 20).

De derecha a izquierda: Bernardo Revuelta, Director de la Fundación Juanelo Turriano, Dirk Bühler, Director de exposiciones del Deutsches Museum de Munich, Javier Uceda Antolín, Rector de la Universidad Politécnica de Madrid, Pepa Cassinello, Subdirectora de Alumnos de la ETSAM y Comisaria de la exposición, Antonio Lamela, fundador del Estudio Lamela, colaborador de la exposición y del libro catálogo, Luís Maldonado, Director de la ETSAM, Rosario FernándezVilla Sra de Torroja, Jose Antonio Torroja, Presidente de la Fundación Eduardo Torroja y colaborador de la exposición y libro catálogo, Dario Gazapo, Director del Departamento de Proyectos de la ETSAM.

Años antes, en el 2008 colaboró también con el homenaje que se organizó en el Instituto de Ciencias de la Construcción Eduardo Torroja, entonces bajo la dirección de Juan Monjo. Se trataba de conmemorar el cumplimiento de los 60 años de la revista Informes de la Construcción. Antonio Lamela escribió un artículo en el libro catálogo de la Exposición denominada «El Espíritu Impreso de una Idea/ The Spirit of an Idea in Print» (18). Posteriormente colaboró en las Jornadas organizadas por la Fundación Eduardo Torroja sobre «Innovación en Construcción» con motivo del cumplimiento de los 80 años del Instituto de Eduardo Torroja. 


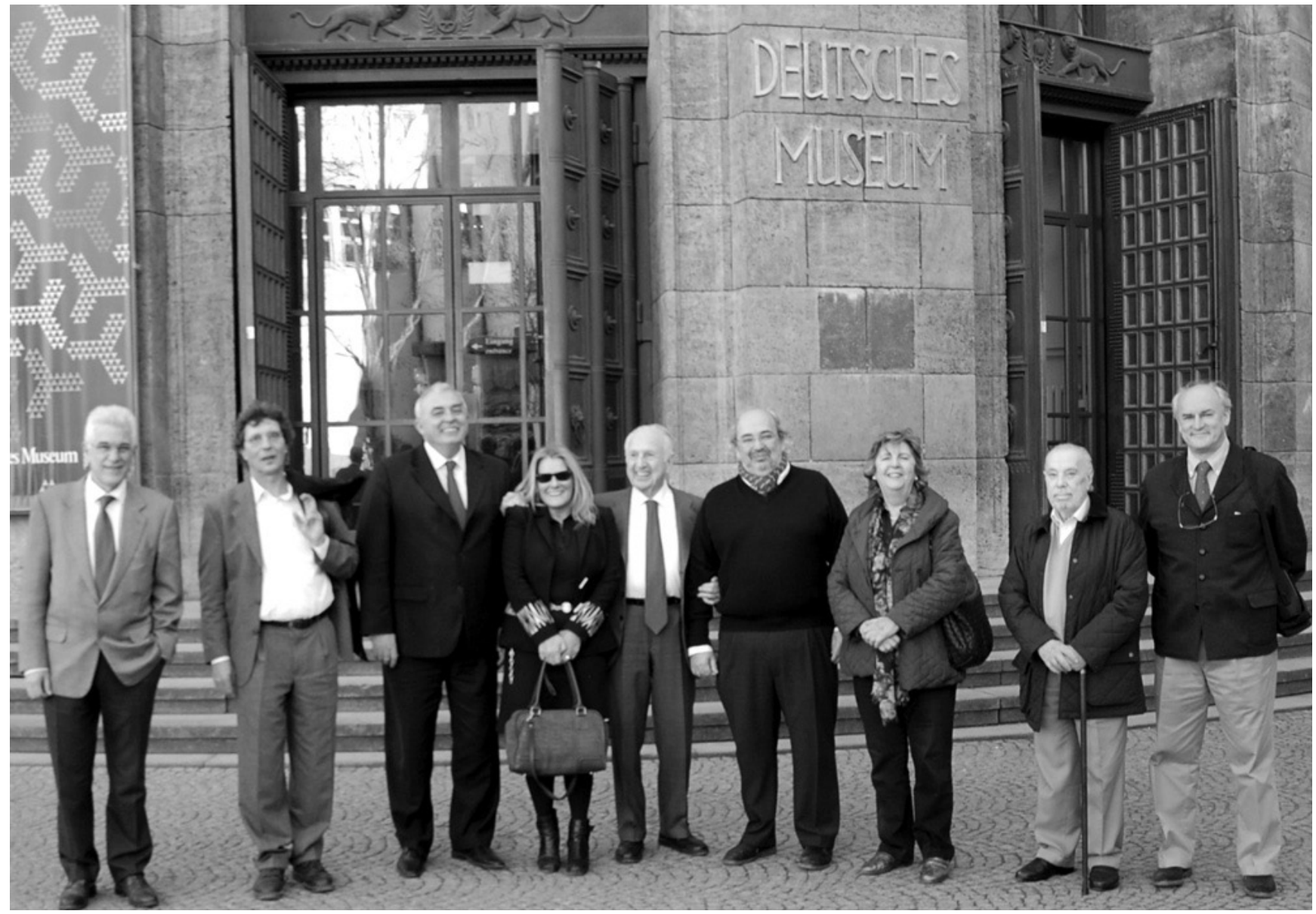

Figura 20. Deutsches Museum de Munich. 12 de marzo 2011.

Desde el 2011 colaboró también en la creación de ALUMNIA, la Asociación de Antiguos Alumnos de la ETSAM. No dudó ni un momento en aceptar formar parte de la primera Junta Directiva y ayudarnos en el difícil camino de convertirla en realidad.

Nuestro agradecimiento a su generoso e insoslayable afán.

\section{DE SU LEGADO}

Tal y como dijo Eduardo Torroja en su famosa carta «A los que colaborasteis conmigo», lo importante no es solo lo que queda ya hecho sino lo que en potencia queda. Su Escuela, que en manos de su hijo Carlos, continua viva construyendo día a día nuevos retos al compás de la siempre cambiante vanguardia internacional, ambicionando la innovación como motor del progreso de la sociedad.

Como siempre que desaparece una gran persona, Antonio Lamela también nos deja vacíos difíciles de llenar. Para quienes tuvimos el privilegio de conocerle desde donde nace nuestra memoria, no habrá lugar para el olvido.

\section{REFERENCIAS}

(1) La revista Informes de la Construcción ha publicado los siguientes artículos de Antonio Lamela: 1958 vol $11 \mathrm{n}^{\circ} 103$ Edificio de Viviendas C/ Segovia en Madrid, 1958 vol $11 \mathrm{n}^{\circ}{ }_{106}$ Viviendas y Oficinas C/ O'Donnell 33, 1960 vol $12 \mathrm{n}^{\circ} 120$ Bloque de Viviendas en Madrid, 1960 vol $13 \mathrm{n}^{\circ} 126$ Motel el Hidalgo, 1961 vol $13 \mathrm{n}^{\circ} 128$ Supermercado en Madrid, 1963 vol $16 \mathrm{n}^{0} 153$ Casa de Viviendas en Madrid, 1964 vol $17 \mathrm{n}^{\circ} 164$ Edificio Industrial en Madrid, 1964 vol17 n ${ }^{\circ} 165$ Vivienda Unifamiliar en Madrid, 1965 vol 18 nº 175 Vivienda unifamiliar en Majadahonda, 1967 vol 20 n $^{\circ} 1952$ Obras de A. Lamela: Edificios Sol y La Caleta en Palma de Mallorca, 1968 vol 21 n $^{\circ} 203$ Edificio Administrativo en Madrid, 1968 vol 21 n $^{0} 206$ Centro Princesa en Madrid, 1970 vol 22 nº 219 Edificios Colgados, 1977 vol 30 n $^{0} 293$ Torres Colón en Madrid, 1980 vol $32 \mathrm{n}^{\circ} 317$ Sede Central para el Banco Internacional de Comercio. Madrid, 1980 vol $33 \mathrm{n}^{\circ} 321$ Pirámide de Oficinas y locales comerciales en Madrid, $1982 \mathrm{vol} 33 \mathrm{n}^{\circ} 330$ Conjunto residencial comercial y de oficinas «Las Francesas». Valladolid, 2005 vol 57 nº 499-500 La sostenibilidad, un reto global ineludible, 2006 vol $58 \mathrm{n}^{0} 501 \mathrm{Nueva}^{\circ}$ Área Terminal (NAT) del aeropuerto de Madrid Barajas.

(2) Cassinello, P. 2008: El Espíritu Impreso de Una Idea/ The Spirit of an Idea in Print. Libro catálogo exposición homenaje a la revista Informes de la Construcción en su 60 cumpleaños. IETcc- CSIC.

(3) Cassinello, P. 2013: Eduardo Torroja 1949. Strategy to industrialise housing in post-World War II. P.p 125-127. Ed. Fundación Eduardo Torroja y Fundación Juanelo Turriano. 
(4) Costa, L. 1934: Razones de la Nueva Arquitectura. Ministerio de Educación Brasil.

(5) Glastra van Loon, F.P. 1957: Schokbeton en la prefabricación. Informes de la Construcción vol 9 nº 87. Ed. Instituto Técnico de la Construcción y del Cemento. Madrid.

(6) Cassinello, N. 2013: Economic Outlook of Spanish housing industry in 1949 and the relevance of the Contest of the Instituto Eduardo Torroja. p.p 203-219. Artículo en libro; Eduardo Torroja 1949. Strategy to industrialise housing in post-World War II. Ed. Fundación Eduardo Torroja y Fundación Juanelo Turriano.

(7) Esteban, C. 2017: Antonio Lamela y Torres Colón p.p22. Ed. General de Ediciones de Arquitectura. Valencia.

(8) Manterola, J. 1985: La estructura resistente de los edificios altos. Informes de la Construcción vol 37, $\mathrm{n}^{\circ} 371$. IETcc- $^{\circ}$ CSIC.

(9) Cassinello, F. 1974: Hormigoneria. p.p 496-499. Ed. Rueda. Madrid

(10) Lamela, A. 1977: Torres Colón en Madrid. Artículo en Informes de la Construcción vol 30 n $^{0}$ 293. IETcc-CSIC.

(11) Cassinello, P. 2008: El Espíritu Impreso de Una Idea/ The Spirit of an Idea in Print. p.p 65. Libro catálogo exposición homenaje a la revista Informes de la Construcción en su 60 cumpleaños. IETcc- CSIC

(12) Lamela, A. 2006: Nueva Área Terminal (NAT) del aeropuerto de Madrid Barajas. Informes de la Construcción. vol 58 $\mathrm{n}^{\mathrm{O}}$ 501. IETcc-CSIC

(13) Lamela, A. 2015: La Terminal T4 del aeropuerto Madrid-Barajas como referencia en la colaboración de arquitectos e ingenieros. ROP. Revista de Obras Públicas. Colegio de Ingenieros de Caminos, Canales y Puertos.

(14) Lamela, C. 2002: Nueva área Terminal del aeropuerto Madrid-Barajas. Informes de la Construcción vol $54 . \mathrm{n}^{\circ} 479$. IETcc-CSIC.

(15) Schlaich, M. 2015: Pabellón de Estado del aeropuerto de Madrid-Barajas. ROP. Revista de Obras Públicas. Colegio de Ingenieros de Caminos, Canales y Puertos.

(16) Lamela, A. 2007: Estrategias para la Tierra y el Espacio: Geoismo y Cosmoismo. Ed. S.L.U ESPASA LIBROS.

(17) Lamela A., 2010: Félix Candela. p.p 169-176. Artículo en libro «Félix Candela- Centenario-Centenary». Ed. Universidad Politécnica de Madrid y Fundación Juanelo Turriano.

(18) Lamela, A. 2008: La revista Informes de la Construcción. p.p 247-254. Artículo en libro El Espíritu Impreso de Una Idea/ The Spirit of an Idea in Print. Catálogo exposición homenaje a la revista Informes de la Construcción en su 60 cumpleaños. IETcc- CSIC.

Nota: las imágenes pertenecen a los archivos: de Estudio Lamela, la revista Informes de la Construcción, y Estudio Cassinello. 